\title{
Distribuição de renda e crescimento econômico
}

\author{
RODOLFO HOFFMANN
}

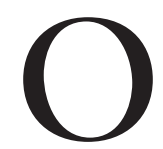

Crescimento econômico dos países constitui, sem dúvida, um tema central da ciência econômica, desde a obra fundamental de Adam Smith, intitulada Uma investigação sobre a natureza e as causas da riqueza das nações, publicada em 1776. E a distribuição da renda tem sido também um tema básico das ciências sociais, inclusive da Economia. Outro economista clássico, David Ricardo, escrevendo no começo do século XIX, considerou que o principal objetivo da Economia Política (hoje denominada Ciência Econômica ou, simplesmente, Economia) era explicar a distribuição do produto nacional entre proprietários de terra, donos de capital e trabalhadores, na forma de renda, lucros e salários respectivamente. Esse problema é conhecido hoje como "distribuição funcional da renda". Enquanto nas escolas de pensamento econômico clássica e marxista há explicações distintas (embora integradas) para a determinação dos salários, dos lucros (e juros) e da renda da terra, associando cada uma dessas remunerações a diferentes classes sociais, a escola neoclássica procura unificar a explicação da remuneração dos fatores de produção com base nos conceitos de produtividade marginal e de equilíbrio de mercado.

Dentro da escola de pensamento neoclássico, os grandes temas do desenvolvimento econômico foram relegados a um segundo plano durante as primeiras décadas do século XX, a favor do que hoje se conhece como microeconomia. Esses temas voltaram a ganhar importância após a depressão iniciada em 1929 e a "revolução" keynesiana na corrente neoclássica. Na marxista, a distribuição da renda nunca deixou de ser tema central. Basta lembrar a polêmica sobre a "Doutrina da Miséria Crescente" de Marx.

Em comparações internacionais, os países latino-americanos em geral, e mais particularmente o Brasil, destacam-se pela elevada desigualdade da distribuição da renda (1). A explicação dessa desigualdade teria de ser procurada na formação e evolução econômico-social dessas antigas colônias de Portugal e Espanha. Um aspecto fundamental foi, sem dúvida, a elevada concentração da posse da terra, especialmente quando a economia desses países tinha como núcleo a produção e exportação de produtos primários. No caso do Brasil, Furtado (1967: cap. VIII) destaca a extrema concentração da renda na economia açucareira colonial. O mesmo autor, ao analisar as conseqüências da abolição do trabalho escravo, afirma que 
"praticamente em nenhuma parte houve modificações de real significação na forma de organização da produção e mesmo na distribuição da renda" (Furtado, 1967: 149).

Nos primeiros anos da década de 60, era generalizada, dentro da "esquerda" brasileira, a idéia de que as "reformas de base", incluindo uma ampla reforma agrária, seriam indispensáveis para que a economia nacional pudesse crescer. Achava-se que somente com essas reformas seria criado um mercado nacional para uma produção crescente.

No livro intitulado Um projeto para o Brasil, publicado em 1968, Celso Furtado discute como a elevada desigualdade da distribuição da renda no país condiciona um perfil da demanda global que inibe o crescimento econômico. Ele mostra como a tendência estrutural para a concentração da renda favorece o subemprego de fatores característico das economias subdesenvolvidas. Assinala que a concentração da renda causa uma grande diversificação das formas de consumo de grupos privilegiados. Isso beneficia as indústrias produtoras de bens de consumo duráveis, mas as dimensões reduzidas do mercado de cada produto impedem o aproveitamento das economias de escala, fazendo com que estas indústrias operem com custos relativamente altos. Em outro trabalho publicado no mesmo ano, ao analisar as conseqüências da política econômica do governo militar instaurado pelo golpe de abril de 1964, ele afirma que "provocou-se maior concentração da renda ... quando se tem amplamente reconhecido que o maior obstáculo ao desenvolvimento do país está na já excessiva concentração da renda" (Furtado, 1968b: 19).

É interessante notar que Furtado (1968a) ilustra seus argumentos com dados esquemáticos sobre a distribuição da renda no Brasil (citando um trabalho da CEPAL, que certamente se baseou nos resultados do Censo Demográfico de 1960), assinalando que os $1 \%$ mais ricos e os $50 \%$ mais pobres se apropriavam de parcelas idênticas da renda nacional: 18,6\%. De acordo com esses dados, os 10\% mais ricos ficavam com 41,3\% da renda nacional. Utilizando os dados da PNAD de 1999, verifica-se que na distribuição das pessoas residentes em domićlios particulares conforme seu rendimento familiar per capita, as frações da renda total apropriadas pelos $50 \%$ mais pobres, pelos $1 \%$ mais ricos e pelos $10 \%$ mais ricos foram, respectivamente, $12,3 \%, 13,3 \%$ e 47,4\%. Em 1968, Celso Furtado já considerava que a concentração da renda era o maior obstáculo ao desenvolvimento do país!

Logo após a divulgação dos dados do Censo Demográfico de 1970, dois estudos mostraram um grande crescimento da desigualdade da distribuição da renda no Brasil entre 1960 e 1970: os de Fishlow (1972) e Hoffmann \& Duarte (1972). Esse aumento de desigualdade transformou-se em elemento importante na crítica da política econômico-social dos governos militares (2). 


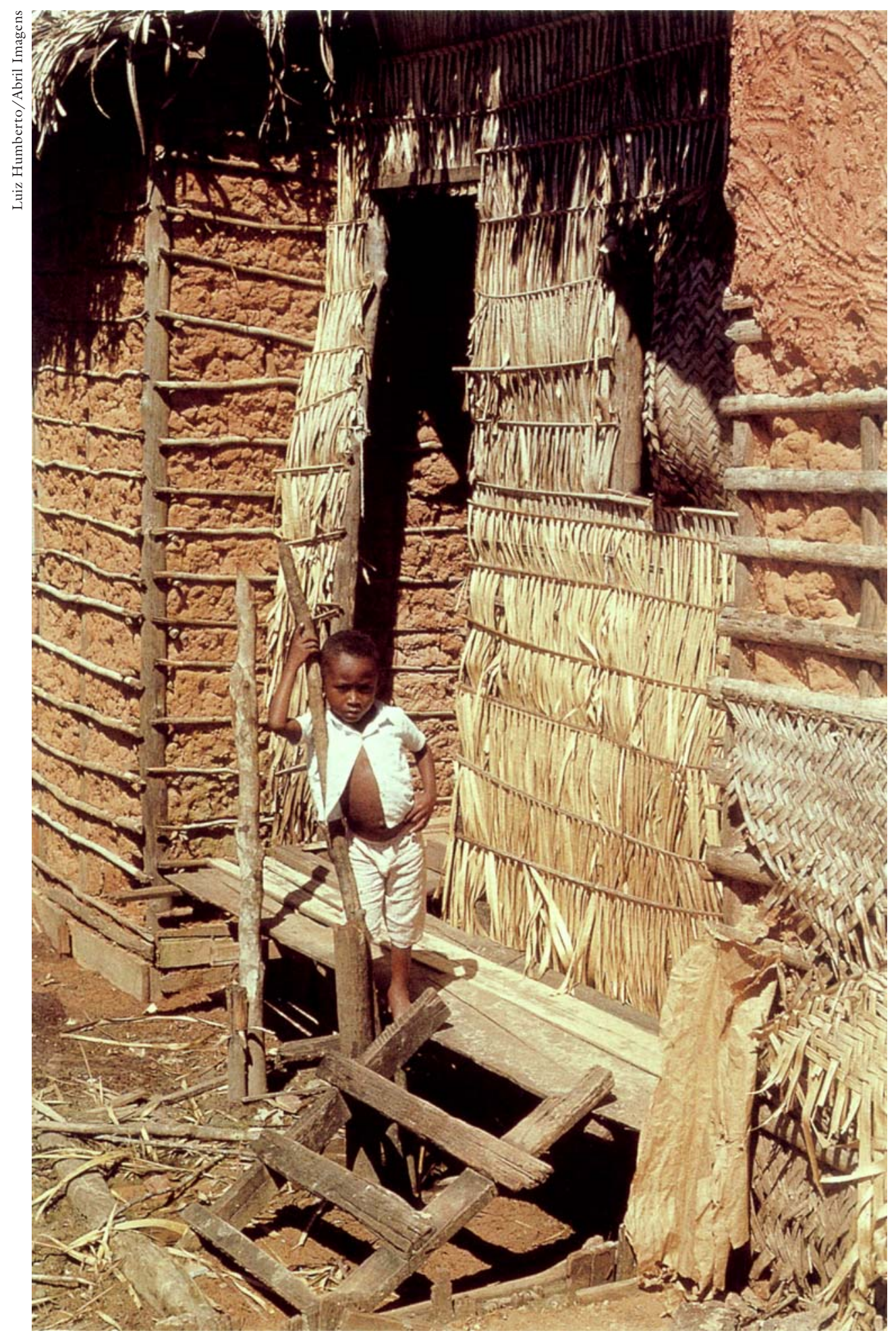

Criança pobre em frente à casa de parede de pau-a-pique na favela do Lixão, em Brasilia (DF)

Inicialmente houve quem colocasse em dúvida os resultados estatísticos. Um economista da estatura de Mario Henrique Simonsen, citando os trabalhos de 
Hoffmann \& Duarte, afirmou que "o debate sobre o aumento de concentração de rendas de 1960 para 1970 só pode ser sustentado com uma boa dose de leviandade estatística" (Simonsen, 1972: 50). Em princípio, é correto analisar qualquer dado estatístico com cuidado, questionando sua validade. Cabe ressaltar, entretanto, que havia várias outras informações indicando o aumento da desigualdade entre 1960 e 1970, além da comparação entre dados dos Censos Demográficos - por exemplo, o crescimento da mortalidade infantil em São Paulo. Como entender que, num período de rápido crescimento econômico, a miséria estivesse matando mais crianças?

O trabalho de Langoni (1973), realizado com o apoio do então ministro da Fazenda, professor Antonio Delfim Netto, foi fundamental para estabelecer um consenso sobre o aumento da desigualdade entre os nos 60 e 70. Com isso, o aspecto polêmico passou a ser a interpretação do fenômeno, com alguns autores enfatizando a política governamental (políticas econômico-sociais, incluindo a repressão a movimentos sociais), enquanto outros consideravam que a maior dispersão das rendas relativas refletia, essencialmente, um mercado no qual ocorria um crescimento da demanda por mão-de-obra mais qualificada sem o correspondente crescimento da oferta a curto prazo.

De acordo com estas duas "teorias", seria de se esperar uma redução da desigualdade quando os "fatores" explicativos mudassem. Depois de quase 30 anos, e após longo período de crescimento lento, a oferta de mão-de-obra qualificada não se tornou relativamente menos escassa? E por que a abertura política não trouxe uma diminuição da desigualdade econômica? Tudo se passava como se a desigualdade, depois de estabelecida, tivesse forte inércia para variações no sentido decrescente.

O que ocorreu foi a inflação acelerada contribuir para aumentar ainda mais a desigualdade da distribuição da renda no país, que atingiu um pico em 1989, no último ano do governo Sarney. De acordo com os dados da PNAD (Pesquisa Nacional por Amostra de Domicílios) de 1989, naquele ano o índice de Gini do rendimento das pessoas ocupadas com rendimento positivo atingiu 0,630 (IBGE, 1997: 144). Isso colocava o Brasil como o mais desigual entre os países do mundo com dados confiáveis sobre a distribuição de renda.

A inflação elevada contribui para aumentar a desigualdade da distribuição da renda. É necessário reconhecer, entretanto, que a inflação elevada faz com que as pessoas errem mais ao declarar seu rendimento e isso introduz nos dados um "ruído" adicional que aumenta as medidas de desigualdade (Ver Hoffmann, 1995 e 1998). Por outro lado, a desigualdade dos rendimentos declarados não capta as perdas que a inflação causa no valor real dos salários dos pobres após seu pagamento, enquanto os relativamente ricos têm muito mais facilidade de proteger seus rendimentos da erosão inflacionária, colocando-os em fundos bancários. 
Em 1993, novamente com inflação elevada, o índice de Gini da distribuição do rendimento de todas as fontes das pessoas economicamente ativas com rendimento positivo era igual a 0,605 e em 1999 havia diminuído para 0,572 - um valor semelhante ao de 29 anos antes, em 1970, após a década em que havia ocorrido um substancial e polêmico aumento da desigualdade. Cabe assinalar que a redução da desigualdade entre 1993 e 1999 foi muito menor quando se considera a distribuição de todas as pessoas residentes em domićlios particulares, ordenando-as conforme seu rendimento familiar per capita. O índice de Gini diminuiu de 0,609 em 1993 para 0,600 em 1999. Trabalho recente de Barros et al. (2000a), analisando a distribuição de rendimento domiciliar per capita de 1977 a 1999, comprova a “inaceitável estabilidade da desigualdade de renda no Brasil”.

Tendo em vista a história dos países industrializados (particularmente a Inglaterra, os Estados Unidos e a Alemanha), Kuznets (1955) afirma que "pode-se admitir que há uma longa oscilação da desigualdade na estrutura secular da distribuição da renda: aumento nas fases iniciais do crescimento econômico, quando foi mais rápida a transição da civilização pré-industrial para a industrial; tornando-se estável durante um período, e diminuindo nas fases posteriores". Adiante ele sugere que os países subdesenvolvidos passariam provavelmente pelas mesmas fases, com um aumento da desigualdade no início da industrialização e uma posterior diminuição da desigualdade. Essa proposição passou a ser conhecida como "lei de Kuznets da variação da desigualdade, conformando graficamente um $U$ invertido.

Interpretações um tanto mecanicistas dessa "lei" foram usadas para "explicar" o crescimento da desigualdade no Brasil entre 1960 e 1970. É interessante notar que Kuznets (1955) terminava sua exposição assinalando que a análise econômica stricto sensu é insuficiente para entender o crescimento econômico e a distribuição da renda, e afirmando que "trabalho efetivo nessa área exige que a análise se desloque da economia de mercado para a economia político-social".

É certo que no período do "milagre" houve, no Brasil, crescimento econômico acompanhado por aumento na desigualdade da distribuição da renda. Mas, mesmo nesse caso, não é correto dizer que o crescimento tenha sido a "causa" do aumento da desigualdade (ver Hoffmann, 1973).

Bonelli \& Ramos (1993) apontam para uma associação negativa entre crescimento econômico e desigualdade no Brasil no período de 1977 a 1986. Eles concluem que o crescimento pode ser uma arma para combater tanto a pobreza como a desigualdade, pois, além de elevar a renda geral, pode estar associado ao crescimento da fração da renda total recebida pelos estratos mais pobres (Veja-se também Ramos, 1990). Assim, mesmo considerando-se apenas a experiência brasileira nos últimos 40 anos, há exemplos de períodos de crescimento seja com redução, seja com aumento da desigualdade. 
$\mathrm{Na}$ última década aumentou substancialmente a literatura que usa dados de um grande número de países para verificar como o crescimento econômico é afetado pela desigualdade da distribuição da renda em cada país (3), pelo tipo de governo (mais ou menos democrático), pela desigualdade da distribuição da terra etc. Uma revisão dessa literatura em 1994 já mostrava que havia evidências de que a desigualdade da distribuição da renda estava inversamente associada com o crescimento econômico subseqüente (Alesina \& Perotti, 1994: 364) (4). Há várias maneiras pelas quais a desigualdade da distribuição da renda pode afetar o crescimento, incluindo o fato de um perfil da demanda extremamente diferenciado impedir o aproveitamento das economias de escala. Alesina \& Perotti encontraram apoio, nos dados internacionais, para a tese de que a desigualdade elevada causa instabilidade sócio-política a qual, por sua vez, dificulta o crescimento econômico. Embora haja efeitos econômicos diretos da forma da distribuição da renda sobre o crescimento econômico, a relação entre essas variáveis seria devida, pelo menos em parte, ao fato de maior desigualdade favorecer maior instabilidade político-social.

Independentemente de se considerar que a redução da desigualdade seja uma condição importante para promover o crescimento econômico, parece haver um consenso, no Brasil, de que essa redução é um objetivo em si mesmo, indispensável para que se possa reduzir mais rapidamente a pobreza. E, quando se fala na necessidade de reduzir a desigualdade da distribuição da renda no Brasil, muitos imaginam um processo de redistribuição que iria reduzir apenas a renda dos extremamente ricos.

Na revista Veja de 12 jul. 2000, foram divulgados dados sobre as 2.745 pessoas que, na declaração de renda referente a 1998, tinham rendimento superior a meio milhão de reais por ano (mais de R $\$ 40$ mil por mês). Essas 2.745 pessoas correspondiam apenas a $0,0045 \%$ das economicamente ativas com rendimento no país, de acordo com a PNAD de 1998. Uma estimativa da renda dessas 2.745 pessoas indica que recebiam cerca de $0,7 \%$ da renda total declarada na PNAD de 1998. É evidente que os extremamente ricos devem ter participação importante em um processo de redistribuição. Mas é preciso deixar claro que os extremamente ricos não constituem base suficiente para uma alteração substancial da distribuição da renda no Brasil.

De acordo com dados da PNAD de 1999, quando se ordenam todas as pessoas residentes em domicílios particulares conforme seu rendimento familiar per capita, os 10\% mais ricos, que ficam com $47,4 \%$ do rendimento total, têm rendimento per capita igual ou maior que $\mathrm{R} \$ 560$, e os $5 \%$ mais ricos, que ficam com pouco mais de um terço do rendimento total, têm rendimento igual ou maior que R\$900. Fazendo uma correção para a subdeclaração dos rendimentos, pode-se afirmar que quem tem rendimento familiar per capita de R\$ 1000 ou mais está entre os $10 \%$ mais ricos, e quem tem rendimento familiar per capita de R\$ 2000 ou mais está entre os $5 \%$ mais ricos. 
Uma objeção sempre levantada contra as propostas de redistribuição da renda é a da falta de credibilidade do governo. Ninguém quer aumento de impostos para alimentar a corrupção. A credibilidade do governo perante a população constitui condição essencial para que ele possa promover ações no sentido de reduzir a desigualdade. Associada a ela está a questão da distribuição do gasto social do governo, que freqüentemente beneficia mais os relativamente ricos do que os relativamente pobres (5).

Embora haja consenso (pelo menos aparente) sobre a necessidade de diminuir a desigualdade, toda medida específica gera polêmica. Deve-se ou não cobrar anuidades nas universidades públicas? Deve-se ou não taxar as aposentadorias de funcionários públicos acima de determinado nível? A Receita Federal pode ou não usar as informações decorrentes da cobrança da CPMF para localizar sonegadores? Em quanto deve aumentar o salário mínimo?

Muitas pesquisas mostram uma associação da desigualdade da distribuição da renda no Brasil com o nível e a distribuição da escolaridade (6). O aumento acelerado da escolaridade é uma estratégia que levaria ao crescimento econômico com menor desigualdade.

Muitas dessas pesquisas se baseiam na teoria do capital humano. Desnecessário dizer que a própria expressão "capital humano" é contraditória com o conceito marxista de capital. Mas, a idéia de que a remuneração de um trabalhador deva crescer com a sua escolaridade é perfeitamente compatível com essa corrente de pensamento (Veja-se, por exemplo, Rowthorn, 1982).

É provável que a importância da educação como determinante do rendimento das pessoas e da sua desigualdade esteja superestimada nas análises econométricas, simplesmente porque não se dispõe de boas medidas para vários outros determinantes da renda, que estão positivamente correlacionados com a escolaridade (7). Mas, o aumento da escolaridade também é um objetivo em si, considerando-se que ela favorece a participação mais plena do cidadão na economia e na sociedade modernas. Assim, apesar das divergências teóricas, há um consenso sobre a necessidade de aumentar rapidamente a escolaridade no país.

Um movimento no sentido de diminuir a desigualdade da distribuição da renda no país certamente não pode se basear apenas em determinada política econômica. Na realidade, praticamente toda política econômica tem um impacto, maior ou menor, sobre a distribuição da renda: política fiscal, previdência social, política de crédito, política educacional, reforma agrária etc. Alterações na legislação também podem ter impacto importante. A dificuldade na análise de cada medida é levar em consideração seus diversos efeitos diretos e indiretos, como fica claro na discussão sobre o aumento do salário mínimo. 
Finalmente, cabe ressaltar que as ações de organizações comunitárias e nãogovernamentais podem dar contribuição substancial para reduzir as desigualdades econômico-sociais no Brasil.

\section{Notas}

1 Ver Barros et al. (2000a) e Székely \& Hilgert (2000). Este último trabalho analisa as limitações dos dados disponíveis para comparações internacionais.

2 Ver Lopes (1975) para uma análise das singularidades do debate em um regime com censura e repressão política, quando a análise acadêmica passou a ser uma das poucas vias permitidas de crítica ao sistema. Nessa época, as reuniões anuais da SBPC (Sociedade Brasileira para o Progresso da Ciência) ganharam enorme importância como fóruns de manifestação de críticas ao regime.

3 Note-se a inversão da ordem de dependência em relação à análise de Kuznets, que discutiu como a desigualdade varia em função do crescimento econômico.

4 Ver também Chong \& Calderón (2000), Chang \& Ram e Chong (2000).

5 Cf. Amsberg et al. (2000) e Barros \& Foguel (2000).

6 Ver, por exemplo, Barros \& Mendonça (1993) e Barros, et al. (2000b).

7 A discussão dessa questão nos EUA é encontrada em Bowles (1972; 1973).

\section{Referências bibliográficas}

ALESINA, Alberto \& PEROTTI, Roberto. The political economy of growth: a critical survey of the recent literature. The World Bank Economic Review, v. 8, n. 3, p. 351-371, 1994.

AMSBERG, Joachim von; LANJOUW, Peter \& NEAD, Kimberly. A focalização do gasto social sobre a pobreza no Brasil. In: Henriques, Ricardo (org.), Desigualdade e pobreza no Brasil. Rio de Janeiro, IPEA, 2000.

BARROS, Ricardo P. de \& MENDONÇA, Rosane. Geração e reprodução da desigualdade de renda no Brasil. Perspectivas da economia brasileira 1994. Rio de Janeiro, IPEA, v. II, p. 471-490, 1993.

BARROS, Ricardo P. de \& FOGUEL, Miguel N. Focalização dos gastos públicos sociais e erradicação da pobreza no Brasil. In: Henriques, Ricardo (org.), Desigualdade e pobreza no Brasil. Rio de Janeiro, IPEA, 2000.

BARROS, Ricardo P. de; HENRIQUES, Ricardo \& MENDONÇA, Rosane. A estabilidade inaceitável: desigualdade e pobreza no Brasil. In: Henriques, Ricardo (org.). Desigualdade e pobreza no Brasil. Rio de Janeiro, IPEA, 2000a. 
Education and equitable economic development. Economia, v. 1, n. 1, p. 111-144, jan. 2000b.

BONELLI, Regis \& RAMOS, Lauro. Distribuição de renda no Brasil: avaliação das tendências de longo prazo e mudanças na desigualdade desde meados dos anos 70 . Revista de Economia Política, v. 13, n. 2, 50, p. 76-97, abr./jun. 1993.

BOWLES, Samuel. Schooling and inequality from generation to generation. Journal of Political Economy, 80, S219-S251, maio/jun. 1972.

Understanding unequal economic opportunity. American Economic Review, v. 63, n. 2, p. 346-358, maio 1973.

CHANG, Jih Y. \& RAM, Rati. Level of development, rate of economic growth, and income inequality. Economic Development and Cultural Change, v. 48, n. 4, p. 787 $799,2000$.

CHONG, Alberto. Inequality, democracy and persistence: is there a political Kuznets curve? Latin American and Caribbean Economic Association, Annual Meeting, 5. Rio de Janeiro, 12-14 out. 2000. Anais em CD-ROM.

CHONG, Alberto \& CALDERÓN, César. Institutional quality and income distribution. Economic Development and Cultural Change, v. 48, n. 4, p. 761-786, 2000.

FISHLOW, Albert . Brazilian size distribution of income. American Economic Review, v. 62, n. 2, p. 391-402, maio 1972.

FURTADO, Celso. Formação econômica do Brasil, 7ª̣ ed. São Paulo, Cia. Editora Nacional, 1967.

Um projeto para o Brasil. Rio de Janeiro, Editora Saga, 1968a.

(org.), Brasil: tempos modernos. Rio de Janeiro, Paz e Terra, 1968b.

HOFFMANN, Rodolfo. Considerações sobre a evolução recente da distribuição da renda no Brasil. Revista de Administração de Empresas, v. 13, n. 4, p. 7-17, dez. 1973.

Desigualdade e pobreza no Brasil no período 1979-90. Revista Brasileira de Economia, v. 49, n. 2, p. 277-294, abr./jun. 1995.

Desigualdade e pobreza no Brasil no período 1979-97 e a influência

da inflação e do salário mínimo. Campinas, Economia e Sociedade, n. 11, p. 199-221, dez. 1998.

HOFFMANN, Rodolfo \& DUARTE, João Carlos. A distribuição da renda no Brasil. Revista de Administração de Empresas, v. 12, n. 2, p. 46-66, jun. 1972.

IBGE. Pesquisa Nacional por Amostra de Domicílios - PNAD: síntese de indicadores 1996. Rio de Janeiro, IBGE, 1997.

LANGONI, Carlos Geraldo. Distribuição da renda e desenvolvimento econômico do Brasil. Rio de Janeiro, Editora Expressão e Cultura, 1973.

LOPES, José Sérgio Leite. Sobre o debate da distribuição da renda: leitura crítica de um artigo de Fishlow. In Tolipan, R. \& Tinelli, A.C. (org.), A controvérsia sobre distribuição de renda e desenvolvimento. Rio de Janeiro, Zahar, 1975. 
RAMOS, Lauro R.A. The distribution of earnings in Brazil: 1976-1985. Berkeley, 1990. Tese (Ph.D), Universidade da Califórnia.

ROWTHORN, Bob. Capitalismo, conflito e inflação: ensaios de economia politica. Rio de Janeiro, Zahar, 1982.

SIMONSEN, Mário Henrique. Brasil 2002. Rio de Janeiro, APEC/Bloch, 1972.

SZÉKELY, Miguel \& HILGERT, Marianne. What's behind the inequality we measure? An investigation using Latin American data. LACEA 2000 - Latin American and Caribbean Economic Association, Annual Meeting, 5. Rio de Janeiro, 12-14 de outubro de 2000. Anais em CD-ROM.

RESUMO - CRESCIMENTO econômico e distribuição da renda são temas básicos da teoria econômica e das análises econômicas do desenvolvimento do Brasil, um país com desigualdade extremamente elevada. A análise da desigualdade ganhou especial notoriedade a partir de 1972, depois da publicação dos resultados do Censo Demográfico de 1970. Hoje, parece consensual que é necessário reduzir essa desigualdade, mas toda medida prática nesse sentido gera polêmica.

ABSTRACT - ECONOMIC growth and income distribution are basic themes on economic theories and economic analysis of the development process in Brazil, a country with a particularly high-income inequality. The controversy about income distribution in Brazil became notorious in 1972, after the publication of 1970 Demographic Census results. Today, it seems that there is a consensus about the need to reduce inequality, but every practical measure towards this objective arouses controversy.

Rodolfo Hoffmann é professor do Instituto de Economia da Unicamp, tendo obtido na Esalq-USP os títulos de mestre (1967), doutor (1969), livre-docente (1971) e professor titular (1981). 